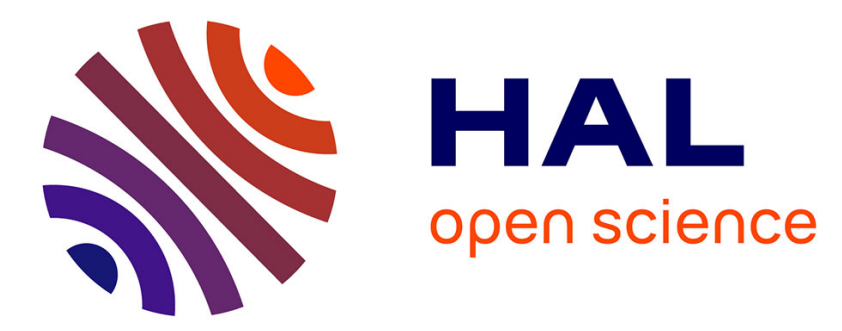

\title{
Towards an Enterprise Social Network to Support Inter-organizational Collaborations
}

Sarah Zribi, Aurelie Montarnal, Frederick Benaben, Matthieu Lauras, Jacques Lamothe, Michael Bailly, Jean-Pierre Lorré

\section{- To cite this version:}

Sarah Zribi, Aurelie Montarnal, Frederick Benaben, Matthieu Lauras, Jacques Lamothe, et al.. Towards an Enterprise Social Network to Support Inter-organizational Collaborations. 16th Working Conference on Virtual Enterprises (PROVE), Oct 2015, Albi, France. pp.421-428, 10.1007/978-3319-24141-8_38. hal-01437909

\section{HAL Id: hal-01437909 \\ https://hal.inria.fr/hal-01437909}

Submitted on 17 Jan 2017

HAL is a multi-disciplinary open access archive for the deposit and dissemination of scientific research documents, whether they are published or not. The documents may come from teaching and research institutions in France or abroad, or from public or private research centers.
L'archive ouverte pluridisciplinaire HAL, est destinée au dépôt et à la diffusion de documents scientifiques de niveau recherche, publiés ou non, émanant des établissements d'enseignement et de recherche français ou étrangers, des laboratoires publics ou privés. 


\title{
Towards an Enterprise Social Network to Support Inter-organizational Collaborations
}

\author{
Sarah Zribi ${ }^{1}$, Aurélie Montarnal ${ }^{2}$, Frédérick Bénabén ${ }^{2}$, Matthieu Lauras $^{2}$, \\ Jacques Lamothe ${ }^{2}$, Michael Bailly ${ }^{3}$ and Jean-Pierre Lorré ${ }^{1}$ \\ ${ }^{1}$ Linagora, 75, Route de Revel, 31400, Toulouse, France \\ \{szribi,jplorre\}@linagora.com \\ ${ }^{2}$ Mines Albi - University of Toulouse, Campus Jarlard, Route de Teillet, 81000, Albi, \\ France \\ \{aurelie.montarnal, frederick.benaben, jacques.lamothe, matthieu.lauras $\} @$ mines-albi.fr \\ ${ }^{3}$ Linagora, 80, Rue Roque de Fillol, 92800, Puteaux, France \\ $\{$ mbailly\}@linagora.com
}

\begin{abstract}
Since the 2000s, social networks have grown spectacularly until they are now regarded as indispensable and introduced as a daily practice of millions of users. Enterprises have become aware of the need and the importance of these collaborative tools, and the concept of Enterprise Social Network (ESN) has now emerged. As such, OpenPaaS is an innovative ESN that aims at facilitating inter-organizational collaborations. In this sense, this paper describes the new OpenPaaS platform to address current issues of ESNs: (i) the management and exchange of large amount of data during inter-organizational collaborations; (ii) the ability of the system to provide synchronous communications between collaborative partners; and finally, (iii) the establishment of transverse collaborations. This last point is a key feature of OpenPaaS, which goal is to automatically generate new inter-organizational coalitions by deducing collaborative processes in response to an opportunity of collaborations brought by any enterprise of the ESN.
\end{abstract}

Keywords: Enterprise Social Network, Collaborative Platform, Support for Inter-Organizational Collaborations, Inter-enterprises Process Deduction.

\section{Introduction}

Social Networking has emerged with the development of a new technology, "Web 2.0", when it became possible for web users to participate actively in the production and disseminating content. They are shifting the Web to turn it into a participatory platform, in which people not only consume content but also contribute and produce new content [O'reilly, 2007]. Over the past few years, Social Networks (SN) have attracted much attention from the web users and they have grown spectacularly until begin now regarded as indispensable and having deeply penetrated our lives.

Companies have become aware of the need and the importance of SN collaborative tools and the concept of Enterprise Social Networks (ESN) has nowadays emerged. However, social working inside organizations is still a wild place that is looking for the right implementation models. In this context, this paper aims at proposing a new 
Enterprise Social Network OpenPaaS that is open-source and supports both inter- and intra-organizational collaborations.

The remainder of this paper is organized as follows. Section 2 presents a brief state of the art on the topic of Enterprise Social Networks and existing collaborative platforms. In Section 3, we sketch an overview of the proposed architecture. Sections 4 and 5 describe the main characteristics of OpenPaaS. Thereafter, Section 6 illustrates an implementation of practical use case study. Finally, the last section concludes and gives insights of future works.

\section{Enterprise Social Networks}

Enterprise Social Networks allow creating or developing friendly or/and professional ties between people. They don't have a unique or fixed form: they are customized to the needs of the organization. In [Li and al., 2012], Altimeter defines ESN as a set of technologies that creates business value by connecting the members of an organization through profiles, updates, and notifications.

Various ESN solutions are available (more than 80 according to the last census of Hervé Bébin in [Bébin, 2012], but only 29 are interested in social collaboration). According to authors in [Koplowitz and al., 2011], [Drakos and al., 2010], [Lecko, 2012], and [Portela, 2012], IBM Connections, Jive SocialBS, NewsGator, Telligent, Confluence, Microsoft SharePoint 2010, Yammer, SocialText, Webex Social and Open Text are among the most important existing solutions.

However, all the aforementioned solutions are proprietary and our principal focus is open-source. Among the existing open-source ones, we find Buddypress, Elgg, Lovdbyless, Ning, Statusnet and People Aggregator. Although those solutions consider the main collaborative concepts resulting from Social Networks, the establishment of a transverse collaborative communication was not treated.

\section{Overall Architecture}

We illustrate the overall architecture of OpenPaaS in Figure 1. Our approach consists on a PaaS (Platform as a Service) technology dedicated to enterprise collaborative applications deployed on hybrid cloud. It provides an innovative Enterprise Social Networks that innovates both at collaborative level by its capacity to leverage heterogeneous cloud technologies at the IaaS (Infrastructure as a Service). 


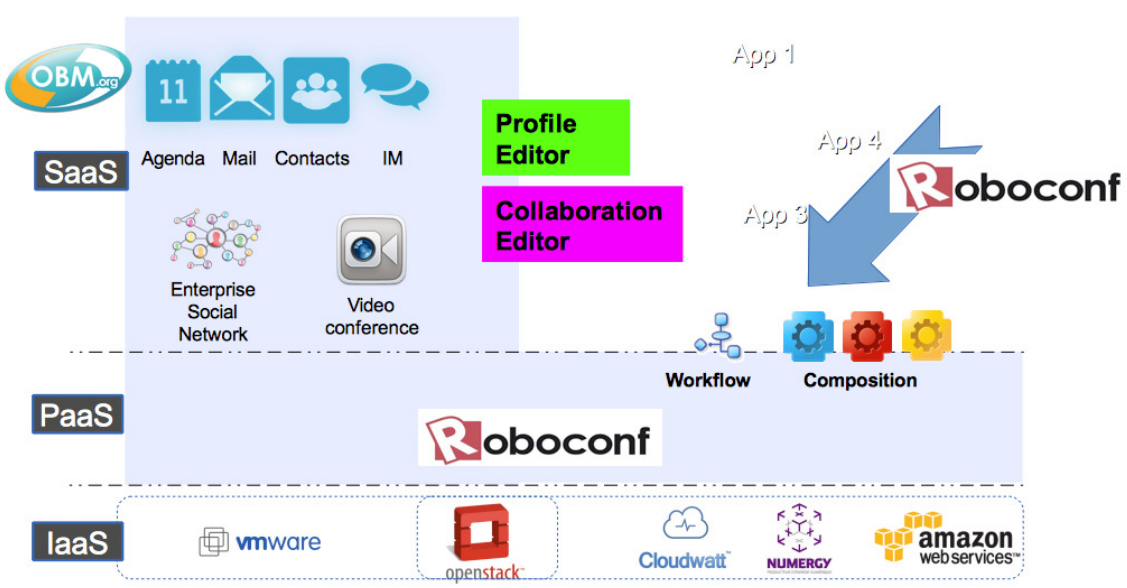

Fig. 1. OpenPaaS Platform.

Within OpenPaaS Platform, a set of collaborative services is made available in an IaaS infrastructure. The ESN is itself a service available in SaaS (Software as a Service) and serves as a point of access to applications deployed in the PaaS. Video Conferencing, messaging, calendar management and file sharing services are included in OpenPaaS platform and are presented in the next section. Moreover, our proposed platform provides Profile and Collaboration Editors tools in order to facilitate the definition of collaborative workflows adapted to the enterprise's needs. Furthermore, OpenPaaS platform includes a Roboconf module that allows both applications deployment and auto-adaption of the infrastructure.

\section{OpenPaaS Collaborative Framework}

\subsection{Social Interaction Services}

OpenPaaS is a reliable social platform in the cloud. Its main contexts of collaboration are:

- Community, which is comprised of members, has a name, can have an avatar and a description. Its main space is an activity stream (compatible on mobile phones) where members can exchange several kinds of messages. Moreover, it has an intrinsic rule regarding the visibility of information that is shared inside. Four types are considered (open, restricted, private and confidential): an open community allows every one to read and to add content, whether or not users are part of the community; a restricted one allows everyone to see the content but only members can contribute; nonmembers of a private community can only see its name, avatar and description; finally a confidential community is invisible for all users that 
are not members. Membership to a community depends on its type. For open ones, the user can freely join it. For the other types, a membership request shall be sent by the user and, then, be validated or denied by the community manager (CM), or an invitation is sent by a $\mathrm{CM}$ to a user to become a member who decides whether to accept or not.

- Project. While communities result from an organic self-organization of the users, a project is more tied to the activity of the company. As such, a project has a start and end dates. Besides, project's members can be users or/and communities.

- Conference consists on a short-lived collaboration. It includes instant messages and WebRTC (Web Real-Time Communication) videoconference.

- Synchronization with external contacts lists, which allows to import contacts from an existing database in order to invite them to join. Currently, OpenPaaS can be connected to Google Contacts API.

- Moreover, other features are ensured within OpenPaaS, such as calendar management and messaging services (Indeed, thanks to $\mathrm{OBM}^{1}$ integration within OpenPaaS) and Sharing of large files between members (which is ensured by an integration of LinShare ${ }^{2}$ within OpenPaaS in order to allow user to add and share files with other users).

\subsection{Automated Creation of New Collaborations}

In addition, a collaborative module has been implemented and aims at facilitating new inter-organizational collaborations: it gathers knowledge on collaborative contexts and needs (profiles and objectives of collaboration) through two modelers and exploits it to create new collaborations: (i) the Profile Modeler lets the enterprises describe their business capabilities (e.g. produce cars) and (ii) the Objective Modeler offers a way to propose new collaborative objectives (e.g. buy cars) and answers to them by setting up the corresponding optimal (e.g. on cost, delivery time, quality criteria, etc.) collaboration (i.e. selecting the best partners to answer the objectives, and order their corresponding capabilities into a business process). A last Collaborative Business Process Modeler allows the users to adapt the latter process and to orchestrate it on the later run-time phase. Figure 2 illustrates these three parts of this knowledge-based system.

\footnotetext{
${ }^{1}$ OBM: http://obm.org/

${ }^{2}$ Linshare: http://en.linagora.com/produits/linshare
} 


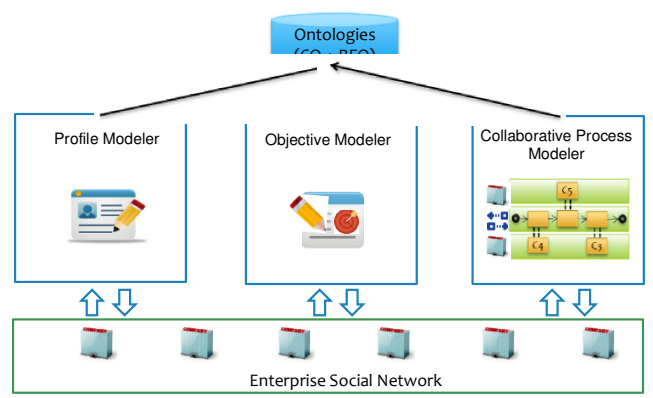

Fig. 2. Overview of the three modelers.

In [9], authors explain the interaction of these three modelers with two ontologies as structured knwoledge bases: the Collaborative Ontology (CO) provides a decomposition of collaborative objectives into sub-objectives, and for each objective the corresponding capabilities to execute in order to fulfill it; the Business Field Ontology (BFO) has been implemented since the latter objectives of the CO remained very generic (e.g. "Buy" which doesn't make the difference between "Buy cars" or "Buy candies"). The CO has been populated y adapting the MIT Process Handbook OWL version [10], and the BFO results from the decomposition of the international business activities in the ISIC Classification (International Standard Industrial Classification of all Economic Activities) [11].

As a first step, the capabilities, described via the Profile Modeler, are represented by their "intrinsic" name, and their inputs and outputs. The capability itself is linked to a capability of the $\mathrm{CO}$, and the input and the output are linked with business fields of the BFO. Then, the objectives described via the Objective Modeler are represented with a link to an objective of the $\mathrm{CO}$ and are linked with a specific domain of the BFO. The third step is executed in back office: it is based on an Ant Colony Optimization algorithm (ACO) that exploits the knowledge included in the ontologies and also gathered by the Profile and Objective Modelers. The overall mechanism of this algorithm can be found in [9]. This ACO allows selecting the optimal set of partners to answer the objectives of the collaboration, and their capabilities. The sequencing of these capabilities into a process is achieved according to a right-to-left process: if one of the outputs of the selected capabilities matches the business field of the objective of the collaboration, it is considered as the final capability of the process. Then, capabilities are linked one to each other by making a correspondence between the input of a capability and the output of the previous capability. The deduced process can be downloaded as a file, which can now be opened, analyzed and potentially adapted by the users in the Collaborative Process Modeler.

For a better understanding of these steps, a use-case is given and detailed in the next section. 


\section{Use Case Validation}

In order to constitute the fulfillment of the OpenPaaS platform, to illustrate the work, we present hereafter a practical use-case that meets the needs of the company SuperCookie that produces cakes with fruits, and which is actually looking for a new collaboration to supply the fruits.

First of all, we start by creating a collaboration context: a use case participant creates a community inside the ESN and chooses its visibility. Second, he/she invites other people to join. Those who respond by accepting are considered as members and can start sharing messages inside the community's activity stream. They use the most simple type of message, that is basically a text, attachments and, if the permission is granted, geolocalisation. Each message appears on the community activity stream. Any member of the community can answer the root message, thus creating a discussion thread. In the use case, members conclude that they need help to choose some enterprises to work with, and they decide to use a collaboration opportunity modeler.

\subsection{Profile Modeler}

In Figure 3, SuperCookie declares to be able to "place order" and link it to the corresponding capability of the CO. From a business field point of view, the input of this capability refers to the "Combined office administrative services" and the output to "Wholesale of food and tobacco" and "Processing and preserving of fruits and vegetables". Basically, this means that SuperCookie is able to send order for buying high amounts of fruits. For the rest of the illustrative case, it is assumed that many enterprises have already described their capabilities in their own profiles.

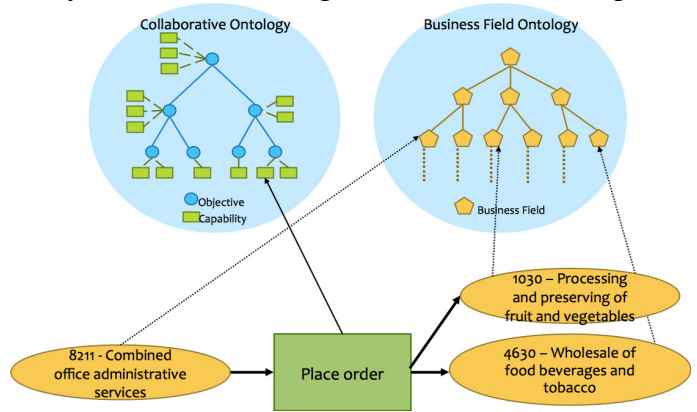

Fig. 3. Example of capability description.

\subsection{Objective Modeler}

The Objective Modeler lets the companies of OpenPaaS to propose new opportunities, for which they need to set up a collaboration (select partners, and deduce the corresponding optimal process). The Figure 4 describes such an objective: here, SuperCookie would like to "buy". As this objective is very generic, the users 
indicate that the purchase refers to the "wholesale of tobacco" since they would like to buy high amounts of food products, and precise it with "processing and preserving of fruits and vegetables".

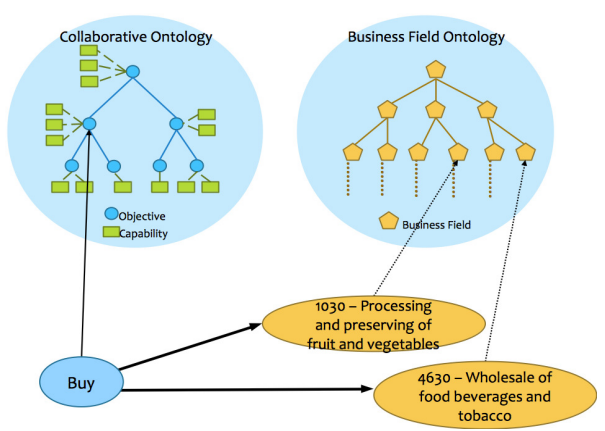

Fig. 4. Example of a collaborative objective.

\subsection{Collaborative Process Modeler}

Finally, the ACO performs the selection of the optimal set of partners and their activities to execute, and order them into a process. This process can be seen in Figure 5. Two companies will take part of the process (SuperCookie and FruitCompany), during the following supply process. A Mediation Information System Pool is directly dedicated to the IT system so that the process can be orchestrated after that the users have adapted this process if needed.

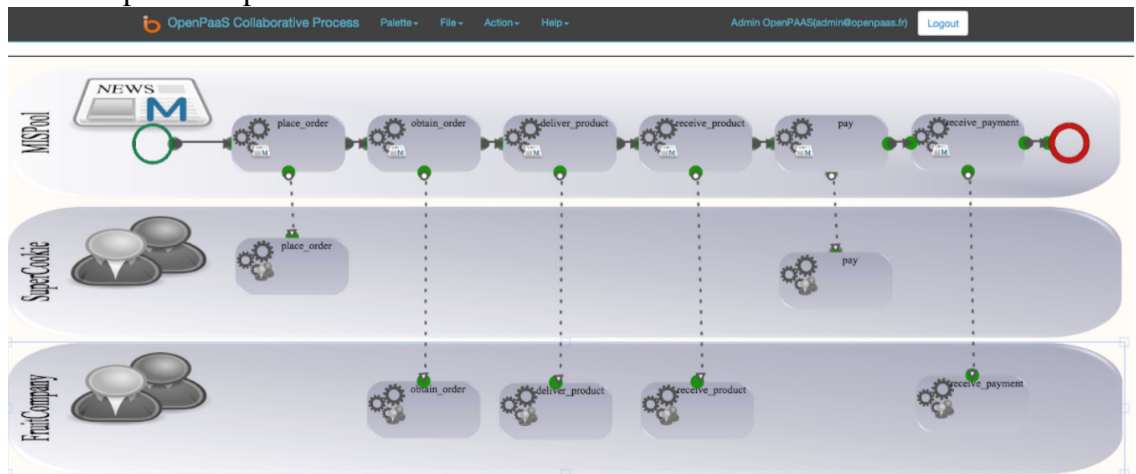

Fig. 5. Example of a deduced collaborative process. 


\section{Conclusion}

This paper presents an innovative Enterprise Social Network which originality relies on its ability to support and facilitate intra- and inter-organizational collaboration by many ways. First, it provides a complete package of social services that helps coordinating the daily working life of the collaborators by providing easy way to share various types of information. This contribution to the current offers of social and professional networking platforms fits a deep need of the companies today, by providing easy-to-use tools. More than facilitating coordination among collaborators, it also provides a service to create new collaborations to fit current business opportunities of the OpenPaaS' users. The optimal selection of partners (and consequently of their capabilities) can, for example, help the enterprises in their bidding process: it can indeed be performed on a very large scope of candidate partners and thus provides quickly an efficient set of partners. Then, the sequencing of these capabilities into a business process that can be opened in a modeler lets the companies to easily adapt it (according to their specific preferences), and then orchestrate it. Besides, works industrialization should be taken in order to stabilize and improve its usability for a wide number of users. Furthermore, to enrich OpenPaaS's features collaborative real-time services (e.g. editing text documents, spreadsheets, business process modeler) need to be studied.

\section{References}

1. Portela, A. (2012). Implantation et usages d'un réseau social d'entreprise: l'expérience d'Astral.

2. Koplowitz, R., Brown, M., \& Dang, J. (2011). The Forrester Wave ${ }^{\mathrm{TM}}$ : Enterprise Social Platforms, Q3 2011.

3. Lecko (2012). Réseaux sociaux d'entreprise (tome 4) : urbanisation du SI Social : entre gouvernance, technologie et usage: http://www.lecko.fr/etude-reseaux-sociaux- dentreprise-tome-4.html

4. Drakos, N., Mann, J., Rozwell, C., Austin, T., \& Sarner, A. (2010). Magic quadrant for social software in the workplace. Gartner RAS Core Research Note G, 207256.

5. O'reilly, T. (2007). What is Web 2.0: Design patterns and business models for the next generation of software. Communications \& strategies, (1), 17.

6. Cavazza, F. (2014). Panaroma des médias sociaux. Mediassociaux.fr. 19 mai 2014.

7. Li, C. (2012). Making the business case for enterprise social networks. ALTIMETER REPORT (February 2012).

8. Bébin, H. (2012). Le marché du RSE en 2012. Réseaux Sociaux et Collaboratifs Internes ou Étendus. 26 juin 2012.

9. Montarnal, A., Barthe-Delanoë Barthe-Delanoë, A. M., Bénaben, F., Lauras, M., \& Lamothe, J. (2014). Towards Automated Business Process Deduction through a Social and Collaborative Platform. In Collaborative Systems for Smart Networked Environments (pp. 443-451)

10. Malone, T. W., Crowston, K., \& Herman, G. A. (Eds.). (2003). Organizing business knowledge: the MIT process handbook. MIT press.

11. United Nations and Statistical Division, International Standard industrial classification of all economic activities (ISIC). New York: United Nations, 2008. 